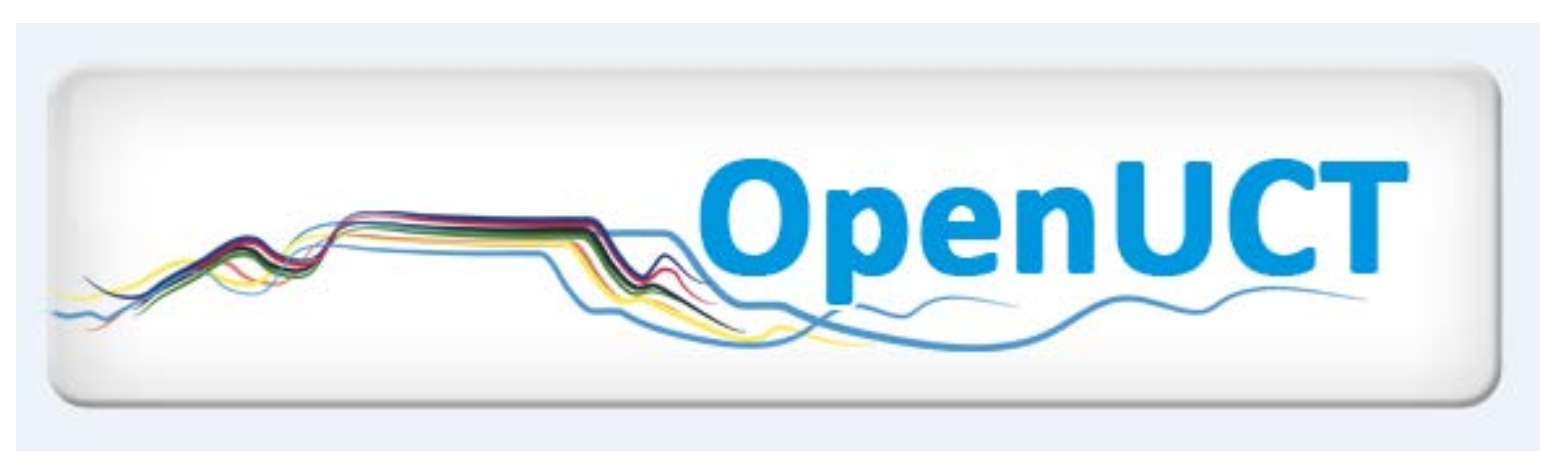

This is the post-print of Paxton, M., van Pletzen, E., Archer, A., Arend, M. \& Chihota, C. 2008. Writer's stance in disciplinary discourses: a developmental view. Southern African Linguistics and Applied Language Studies. 26(1): 107-118. DOI:

10.2989/SALALS.2008.26.1.9.424.

It is made available according to the terms of agreement between the author and the journal, and in accordance with UCT's open access policy available:

http://www.openuct.uct.ac.za/sites/default/files/UCTOpenAccessPolicy.pdf, for the purposes of research, teaching and private study. 


\title{
Writer's stance in disciplinary discourses: a developmental view
}

\author{
Moragh Paxton, Ermien van Pletzen, Arlene Archer, Moeain Arend and Clement \\ Chihota \\ Centre for Higher Education Development, University of Cape Town.
}

\begin{abstract}
An approach to writer's stance will differ depending on whether one looks at it from an analytic theoretical perspective or a developmental perspective. This article describes a training activity in the Writing Centre at the University of Cape Town which led the authors to evaluate the concept of writer's stance as used in corpus studies against the way it is used by academic literacy practitioners working in developmental fields. Corpus analysts tend to construct a general and theoretical conceptualisation of writer's stance, while academic literacy practitioners who work in complex developmental fields focus on what actually happens (or needs to happen) when individual readers or writers grapple with texts within particular social environments such as academic disciplines.
\end{abstract}




\section{Introduction}

This paper is an exploration of writer's stance in disciplinary discourses. We believe that an approach to writer's stance in disciplinary discourses will differ depending on whether one looks at it from an analytic theoretical perspective or a developmental perspective. In the paper, we weigh up some of the insights offered by corpus analysts like Hyland (1999, 2000) against those emerging from the work of academic literacy practitioners such as Granville and Dison 2005, Ivanic 1997, Leibowitz 2000, Lillis 1997 and researchers in the Language Development Group at the University of Cape Town (UCT), who work in a complex developmental field, mediating students' reading and writing practices within particular academic disciplines.

The paper will describe how the concept of writer's stance appears in corpus studies, and consider how the concept relates to a term like 'voice' occurring in academic literacy ${ }^{1}$ literature. This discussion hopes to bring out the way in which corpus studies tend to construct a general and theoretical conceptualisation of writer's stance, while academic literacy practitioners focus on what actually happens (or needs to happen) when individual readers or writers grapple with texts within particular social environments.

We begin by describing a workshop exercise set by Paxton as part of a training programme for consultants working in the Writing Centre at UCT. The exercise was intended to alert consultants to the existence of distinctive conventions in the discourses of different academic disciplines, in order to assist them in working with students who come to the Writing Centre from the full range of disciplines offered at the University. The consultants were asked to analyse a piece of writing from their own academic discipline, using Hyland's conception of writer's stance. The two consultants who contribute to this paper are postgraduate students working in the humanities, one in literary studies, and the other in a specialisation of linguistics, the New Literacy Studies. What emerges from their contributions is that individual texts (or their authors) establish extremely complex relationships with the disciplinary contexts within which they write, relationships that could

\footnotetext{
${ }^{1}$ Academic literacy is understood as the capacity to engage successfully with the demands of academic study in the medium of instruction of the particular educational environment (Cliff and Yeld 2006)
} 
not possibly be captured fully in the more general results of corpus analyses. While one contributor manages to describe fairly general disciplinary conventions for a concept like writer's stance, the other one shows how dependent a particular writer's stance is on the academic and broader social context within which he or she writes. This exercise shows how general definitions of the conventions of disciplinary discourses get complicated in practice, especially in developmental environments where the impact of such definitions on individual educators’ or students’ practices has to be considered.

This insight is then developed by drawing on the research of three members of the Language Development Group, working in the disciplines of economics, engineering and health sciences. These researchers are all exploring the possibilities of building on students' prior discourses as a way of enabling acquisition of new academic discourses and the paper focuses particularly on some of the complexities that arise when educators try to mediate novice academic readers’ and writers’ access to disciplinary discourses. Some of these are:

- lecturers' conflicting understandings of the conventions of a discipline

- the confusing role that textbooks play in modeling disciplinary discourses

- the complex demands that hybrid discourses emerging from applied and interdisciplinary fields make on educators and students

- the extent to which learning to operate in a discourse is a gradual process of apprenticeship rather than a simple application of new knowledge

- the ways in which writing in a new disciplinary discourse often robs students of their individual voices.

The paper ends by considering whether and how corpus studies' perspectives on disciplinary discourses could be used in developmental contexts.

\section{The training workshop}

The Writing Centre is a project within the Language Development Group and employs postgraduate students, registered at UCT, as writing consultants. These consultants are 
drawn from a range of different disciplines ${ }^{2}$ and are trained by members of the Language Development Group in a week long training programme, followed by weekly training workshops through the year. An important aspect of training is that when new consultants join the Writing Centre they begin to familiarise themselves with a variety of different disciplinary discourses so as to be able to assist students with particular discoursal conventions and strategies. It was for this reason that Paxton designed the workshop on disciplinary discourses. She believed that if consultants each undertook a linguistic analysis of their own disciplinary discourse it would give them a metalanguage with which to talk about the features of the discourse with other consultants. It seemed likely that this process of sharing would provide consultants with insights into a range of disciplinary discourses which would inform their consultations with students who have to produce writing in a range of disciplines.

The specific task set for consultants was that they should analyse a text from their own disciplinary discourse to show how expert writers position themselves in their discourse. Hyland's (1999) article “Disciplinary discourses: writer stance in research articles” was provided as a reading in preparation for the workshop. Hyland (1999:103) analyses authors' stance by using five markers. These are:

- Hedges e.g. This is to a large extent the case, possibly, may, could, believe

- Emphatics, which show the writer's certainty in relation to his/her claims e.g. Of course, without doubt, definitely

- Attitude markers, which show the writer's affective attitude e.g. Unfortunately, appropriately, we prefer

- Relational markers, which explicitly address readers and attempt to invoke reader participation e.g. Let us now consider, note that

- $\quad$ Person markers e.g. $I$, we.

The discussion in the workshop provided a wide variety of insights into disciplinary discourses. Two of the participants wrote up their contributions for this article. Three

\footnotetext{
${ }^{2}$ In 2006 there were 10 consultants employed in the Writing Centre doing postgraduate studies in botany, molecular biology, literature, sociology, information literacy, climatology, sociolinguistics, drama and music.
} 
further contributions were added by staff members from the Language Development Group, who were also involved in the Writing Centre’s training programme. These five contributions are presented as separate sections.

\section{Literary theory: Clement Chihota - Writing Centre consultant and Doctoral student of Literature}

Chihota's analysis produced a description of the discourse of literary theory. He looked at the following passage from Outside Literature (1990:106) by Tony Bennet which discusses the concept of genre formation in literature [special text features are added to facilitate our analysis below]:

A MORE succinct statement of the logic of the sociology of genres COULD HARDLY BE ASKED FOR. IT IS TRUE that the ambiguity in Lukacs's terminology - oscillating between the 'facts of life' and the 'truth of life' - reflects a somewhat uneasy compromise between the Simmelian legacy of his earlier sociology of drama and the Marxist base/superstructure conception. None the less, IT IS CLEAR THAT, for Lukacs, the central problems of genre theory concern the decipherment of the relations between socially determined forms of writing so as to reveal the impress of the former on the latter. Literary form, here, flows on from social conditions as their determined effect. Where such conditions remain relatively constant, then so does the repertoire of genres; where, per contra, changing conditions of life cannot be adequately reflected within existing genres, then new literary forms are brought into being to achieve this end. Perhaps, MOST INDICATIVE, however, is Lukacs's contention that a case for genre specificity can be upheld only if a particular form of writing can be shown to rest on and give expression to distinctive social conditions. He thus DISPUTES the view that the historical novel might be regarded as a genre in its own right on the grounds that the answer to the decisive question here - 'which facts of life underlie the historical novel and how do they differ from those which give rise to the genre of the novel in general' - must be: ‘none’. 
In this short passage Chihota found nine hedges (shown in lower case, non-bolded italics). He argues that it is a usual convention within literary discourse to make assertions that sound tentative and speculative. Bold claims usually attract 'armies' of critics who shoot them down and the large number of hedges indicates a way of avoiding or hiding a show of boldness. This does not prevent Bennet from combining hedging with an emphatic (in CAPS): “Perhaps, MOST INDICATIVE, however...”.

There are eight instances of relational markers in the passage (shown in bold lower case type). Relational markers are used quite prolifically to ensure cohesion, since Bennet is articulating a rather 'complicated' argument that requires (for example) crossing from one possibility to the other. The success of Bennet's own argument depends on how favourably he has presented Lukacs's earlier argument. For that reason, he actually hedges on behalf of Lukacs to make the latter's arguments sound as 'well considered' as possible. Thus we see an interesting example of ‘deliberately shoring up’ another’s argument because that argument shores up one’s own: “...most indicative, however, is Lukacs’s contention that a case for genre specificity can be upheld...”

Chihota further argues that it is a standard feature of literary discourse to minimise on attitude markers (only three shown in ITALIC CAPS). Personal opinions are not very welcome in this field and they may be made only sparingly. Through hedging and other methods of communicating 'tentativeness', writers 'earn' the authority to make bold assertions, for example after using hedges to ‘soften’ Lukacs’s assertions, Bennet reaches the point where he can now write, “Lukacs disputes...”.

Through this analysis Chihota manages to extract a number of general principles of the discourse of literary theory which could very well be made explicit to fellow Writing Centre consultants and to students visiting the Writing Centre with their literary essays. While this is a useful starting point in beginning to illustrate some of the conventions of a particular disciplinary discourse, our point here is not that disciplinary discourses are uniform and monolithic structures with unchanging features that could be identified and 
described simply. Instead, we hold the position that writing in a particular discipline involves participation in complex social practices, a major element of which is writers' way of positioning themselves strategically for particular purposes and audiences. This becomes more evident when we look at the text samples and analyses of the next two contributors, where a particular theoretical inclination or area of interest has shaped discourse in particular ways within the broader disciplines of Applied Linguistics and Sociolinguistics.

\section{The ‘New Literacy Studies’ in Applied Linguistics: Moeain Arend - Writing Centre Consultant and Doctoral student of Education}

Arend has chosen to explain the theoretical position of the New Literacy Studies (NLS) theorists and to draw on the arguments of Hyland (1999) to indicate how this particular theorisation has come to have an effect on the writers' stance of NLS theorists.

Arend starts by pointing out that the New Literacy Studies is an independently developed area of theory and research that positions literacy and literacy practices within broader social practice, using mainly ethnographic research methods. As major definer of the NLS, Street (1999) shows how two competing models for literacy, namely the autonomous and the ideological models, have become influential in theorising literacy. Literacy within the autonomous model is seen as a set of decontextualised skills devoid of and separate from any social context (Prinsloo and Breier, 1996). In the autonomous model Street argues that the assumption is made that literacy in itself - autonomously - will have positive and unproblematic effects on the cognitive and social practices of people. Imposing an 'autonomous' view of literacy on writing practices in a particular social context blurs and disguises cultural and ideological assumptions - giving an "opaqueness” to these writing practices - which can easily be presented as though they are neutral and universal (Street, 1996). The ideological model, as an alternative model to the autonomous model, suggests that literacy is a social practice (not simply a technical and neutral skill), "that is always embedded in socially constructed epistemological principles” (Street, 1999). Literacy within the ideological model is always contested in both its meanings and its practices. Therefore Street (1999) argues that literacy practices are always ideological because they 
are embedded within particular world views on literacy. Because these socially constructed epistemological principles have become woven into literacy practices, they compete to dominate and marginalise other literacy practices. Removing the "opaqueness" of takenfor-granted literacy practices has become a key focus of research in the NLS.

Moving to Hyland's work (1999:115), Arend shows how this writer argues that conventions of stance reflect the aspects of a community's values and beliefs about knowledge and knowing (in other words a certain epistemology). Finding this formulation of stance compatible with the way in which the theorists of the NLS position themselves, Arend points out that they prefer to employ the first person "I" and "we" to reflect not only their stance in the text, but also their argument that literacy is a social practice and that social groups and individuals manipulate literacy in a myriad of ways, always more or less personal and all communal. To illustrate this further, he draws on extracts from two articles, by Rios (2005) and Street (1999), which show strong personal commitment to the claims made:

\section{Extract One}

I start from the assumption that literacy is situated in time and space (Barton et al. 2000), so that there are different literacies for different divisions of social time and space, one of these divisions particularly being the unity of the neighbourhood. When I say different literacies for different divisions of social time and space, I do not mean that there are similar literacies for each different context (Rios 2005:135).

\section{Extract Two}

So we developed what I have come to call an ideological model of literacy (Street, 1999:12)

Arend shows how the NLS advocates that it is necessary to illuminate the ideologies that are embedded in texts to gain a better understanding of literacy practices and how they vary from context to context and from social group to social group. The "I” person marker in Extract One is closely linked to the epistemology of the NLS, namely that texts reflect the 
assumptions of a specific social group (and in this case it is those conforming to the theories of the NLS). The use of "I" indicates the author's conscious attempt to remove the "opaqueness" of the position he has chosen to adopt regarding the theorisation of literacy, namely that literacy is embedded in social time and space. Besides the conscious attempt by the writer to make his stance explicit, the use of the person marker "I" serves a further purpose. The NLS refutes the claim that it is literacy that takes hold of people and instead they argue that people take hold of literacy. Inserting the "I" and the "we" into Extracts One, Two and Three reflects the ideology that it is the "I" and the "we" that take hold of literacy - making it explicit that it is people who construct, consume and manipulate texts. Therefore by inserting the "I" and "we" person markers as indicated in the extracts above, the ideology of the NLS is not only illuminated, but the author is made visible, showing that he or she has agency in the production of the text. The "we" in Extract Two also mirrors the NLS argument that literacy is communal, existing in social groups.

The texts chosen for analysis above illustrate the complex moves through which writers position themselves within particular disciplines. While Chihota's example from literary theory illustrates a planned tentativeness and suppression of the individual author's voice, Arend's texts show that writers could also take a far more explicitly personal stance in academic writing. For a novice entering a disciplinary discourse, these text features may appear contradictory and confusing.

It became clear to the authors of this paper that the process of describing and especially enacting the features of disciplinary discourses is not merely a conceptual or theoretical exercise, but a process that needs to unfold developmentally, taking into consideration the complex social environments within which academic literacy practices take shape. In this respect, the authors of this paper adhere to a model of academic literacy best outlined by Street's ideological model (as described in this paper by Arend), in that we wish to draw attention to the complexity of the social world, of institution, discipline and personal authorship, within which writers, both expert and novice, have to position themselves when they engage in what is called academic writing. We hope to begin to outline this complexity 
in the three contributions which follow, drawn from the research of three staff members from the Language Development Group at the University.

\section{Economics: Moragh Paxton - Researcher and Lecturer in the Language Development Group}

Paxton's research into students' acquisition of economics discourse $(2003,2004)$ points to the complexities of distilling a clear conception of a particular disciplinary discourse, in her case, economics. Discussions with lecturers in the discipline and Paxton's own observations of the style prevalent in economics journals seem to indicate that students may be receiving mixed messages about how to take ownership of their ideas and establish an authorial presence when writing in economics. In addition she found that textbook discourse differs quite markedly from 'authentic’ economics discourse.

As part of a larger research project she conducted a brief survey of published professional economics articles in order to find out how the experts established an authorial presence in their professional writing. The journal survey confirmed that much of what Hyland (1999 and 2000) indicates about authorial presence in the hard knowledge areas of the sciences, engineering and biology, is true also of writing in economics. He says that in the hard knowledge areas "researchers typically conceal their rhetorical identities behind a cloak of objectivity, masking their involvement with an array of linguistic detachment” (1999:115). This is seen as strengthening the validity of their findings.

Paxton found that, in economics, this reluctance to portray a prominent authorial presence is achieved in a number of ways. For example, authors avoided the use of the first person, instead making frequent use of third person markers such as The purpose of this study...is, ...it could be argued..., It is clear that..., ... it is advocated. When attitude markers were used to express the writer's affective attitude to propositions, they were used in the third person: Many of the assumptions are open to debate but in the view of the authors, the assumptions are on the conservative side. However, this did not mean that writers 
completely steered away from assuming a strong individual stance - such a stance could be achieved rhetorically by other means than using the first person. An extract from the conclusion to one of these articles illustrates how the writer, while avoiding the use of the first person, uses emphatics to make a strong claim so that the reader is left in absolutely no doubt of the writer's position on the South African government's Growth Employment and Redistribution (GEAR) policy:

While many factors influenced the performance of the economy during 1996-8 there is a prima facie case that the GEAR policy package made a significant contribution to the collapse of growth in South Africa, owing to its emphasis on deficit reduction...

Paxton's interviews with staff in the economics department provided further insights into the ways that professional economists represent themselves in their writing. The convenor of the microeconomics ECO100A course said that the first person singular is used rarely, if at all in economics writing but he pointed out that expert writers might sometimes use the plural 'we'. The other interviewees agreed that it is unusual to see the first person used in economics research and one interviewee commented that the reason for using 'we' is that it allows researchers to share the blame. However, the interviews indicated that there did not seem to be consensus about what lecturers or tutors expect from students. Paxton has further observed that postgraduate students, employed as economics tutors in the ECO100A course, frequently indicate in written feedback on students' essays that the use of the first person is not acceptable in economics. In contrast, some of the lecturing staff seemed more flexible.

Another interviewee said that she wanted to see the emergence of students' own voices in their writing, particularly at postgraduate (Honours) level. She considered that taking a position did not necessarily mean that the students needed to use the first person. She expressed frustration at the fact that students regurgitated information from other authorities and did not take a position. She wanted to see students relate to their own contexts and understandings more - to ‘contextualise' their writing. And yet she expected 
them to do this without using the first person, which may be a confusing requirement for students.

One reason for the mixed messages that are being conveyed to students may be that the discipline of economics is, itself, in the process of change. Becher and Trowler (2001) point out that economics seems to straddle the boundaries of hard versus soft and pure versus applied dimensions of academic disciplines. It started out as a predominantly soft discipline but after the Second World War it began to aspire to the scientific standards of physics, because it was felt that objectivity and mathematical precision would give greater scope and credibility to the discipline. Since then economics has become more strongly theoryorientated and mathematically sophisticated and thus 'harder' (Becher and Trowler 2001).

Paxton found further contradictions in that the discourses and practices of economics textbooks differ markedly from the literacy practices of expert writers in the discipline. Her research indicates that because the economics textbook plays such a powerful authoritative role in undergraduate economics teaching it sometimes provides the only model of the literacy practices of the discipline and thus it impacts on student writing in important ways.

A way in which textbooks achieve a consensual view is by their use of a single voice to control the text and by concealing the other voices. First year economics textbooks make very little use of reference to the primary sources. They usually have no bibliography and little or no in-text referencing. These practices differ from the referencing conventions and practices of the disciplinary community. Textbook writers have developed quite skilful strategies to convey the idea that the entire economics profession shares their beliefs and therefore there is no need to use conventional referencing practices. This single-voicedness of the textbook is problematic for novice readers of economics because if this is the only model of the literacy practices of the discipline that undergraduate students encounter, students may get the impression that single-voicedness is a standard feature of economics discourse. 


\section{The Health Sciences: Ermien van Pletzen - Researcher and Lecturer in the Language Development Group}

Like Paxton, Van Pletzen also draws attention to the ways in which textbooks articulate with disciplinary discourses (2006), while her research also looks at the difficulties presented by the multiplicity of discourses that co-exist in the health sciences. One of the questions she asks is what happens 'between' discourses in strongly multidisciplinary curricula.

She explores these issues with reference to the cluster of disciplinary discourses which constitute the new socially embedded medical curriculum at the University of Cape Town. The curriculum examines health and illness as simultaneously scientific, biomedical phenomena, as well as psychosocial phenomena. Drawing on a spectrum of disciplines, ranging from basic health sciences to the social sciences, the new curriculum presents particularly complex challenges to language development practitioners.

Van Pletzen points out that Ken Hyland (1999:105) speaks of the "major role” that textbooks play in “learners' experience and understanding of a subject by providing a coherently ordered epistemological map of the disciplinary landscape”. Apart from this, textbooks could also "provide a model of literacy practices, how the discipline states what it knows”. However, Hyland also mentions the widely held view that textbooks are “repositories of codified knowledge” rather than formulations or constructions of "new knowledge” in the discipline, and that they are set "apart from the more prestigious genres through which academics exchange research findings, dispute theories and accumulate professional credit” (105). He quotes Bartholomae (1985: 4) to raise the question of whether textbooks successfully induct students into the "peculiar ways of knowing, selecting, evaluating, reporting, concluding and arguing that define the discourse of the community” and reiterates Kuhn’s point that “familiarity with textbooks straitjackets students into disciplinary paradigms” (106). 
According to Van Pletzen this kind of disciplinary 'straitjacketing' can be observed in the medical curriculum, mainly in the attitudes students build up towards writers' stance in these textbooks. Basic health sciences textbooks in particular tend to strip away the social and interpersonal processes through which the discourse community of health scientists arrive at, report and evaluate new knowledge. This gives the impression that new knowledge in the health sciences is always produced and reported completely neutrally, objectively and in ways that need not be contested in the community. Textbooks in the basic health sciences often present knowledge which has been accepted in the community as indisputable fact. Even citations become largely unnecessary, while the writer's stance comes out most strongly at the level of guiding the student reader, a novice in the discipline, through the organisation of the text and the accepted knowledge of the discipline presented in the textbook. Van Pletzen shows that it is misleading, however, to take this kind of textbook discourse for the discourse of the discipline in general. One need only look at articles in science journals to realise that writers of journal articles in the basic health sciences do have to position new knowledge through detailed citation practices and that they often use strategic argument markers and boosters to promote their own data and findings in a highly competitive community. In the case of the basic health sciences, therefore, textbooks could easily give students a stereotyped notion of these disciplines' discourses.

Textbooks mapping out the psychosocial side of human development, against this, tend to retain some of the processes through which knowledge is constructed and communicated in this cluster of social science disciplines. Social science textbooks often retain strong citation practices, weighing up the different bodies of data, theories and explanations that make up knowledge in these disciplines. Hedges, emphatics, relational and attitude markers abound in the process of mapping out the different debates and developments to student readers. A good example of this can be seen in different theories of identity or gender development put forward by developmental psychologists.

Ironically, in Van Pletzen’s view, what often happens ‘between' these clusters of discourses in the medical curriculum, is that students come away with stereotyped notions of both: 
they accept the simplified textbook version of scientific discourse as unproblematic factual knowledge, against which they measure the more circuitous discourses of the social sciences, interpreting them as 'merely' opinions or theories. Students frequently describe writers' discourse in anatomy as purely factual and fixed, and therefore true and worth pursuing as knowledge, while they regard the discourse of psychosocial writers as opinion, unverified, and therefore not a true or specialised form of knowledge. In this respect, the juxtaposition of clearly defined disciplinary paradigms does seem to result in a type of disciplinary stand-off, with students’ disciplinary knowledge and attitudes bracketed separately in ways that may block students from developing a fuller and more nuanced understanding of these discourses and disciplines.

Having said this, Van Pletzen also points out that there is space for exciting new developments 'between' the discourses brought together in the new medical curriculum. The problem-based pedagogy of the curriculum presents students with socially embedded cases of health and illness which they have to analyze and discuss in small group discussions and in writing. The chosen pedagogic framework, as well as the holistic primary health care philosophy of the curriculum, forces students to combine the discourses of the health sciences and the social sciences. The strong practical applied component of medical training, which takes the form of visits to private homes, multilingual communities and health facilities, adds to the array of discourses that students encounter and have to master during their training.

This array of discourses presents huge challenges and raises fascinating questions for academics who are based in the various disciplines, as well as those who work across the disciplines, like language development practitioners. These include challenges and questions such as:

- How do we keep track of what happens ‘between’ discourses when they are applied together in a curriculum?

- Do new hybrid practices and discourses emerge through the ways in which discourses are combined in the curriculum?

- If they do, who models them, and who is in charge of these new forms? 
Van Pletzen finds the last question particularly engaging, pointing out that academic discourses are usually shaped through the interactions of expert users and that these expert users are usually academics who have achieved success in the discourse community and therefore have the power to decide on the norms of the discourse. However, in the Medical curriculum, powerful academics may continue to adhere mainly to their own disciplines. Van Pletzen posits that it may in the end be mainly students themselves who will be most centrally engaged in making hybrid disciplinary knowledge from the array of discourses through their speaking, writing and reading practices in the new medical curriculum. In this way the curriculum may foster changes to discourses, new ways of making and presenting knowledge. What is exciting is that these changes to academic discourses may happen, uncharacteristically for academic settings, to a large extent through the participation of relative novices rather than through the regulation of discourses by expert users.

\section{Engineering: Archer - Co-ordinator of the Writing Centre and Researcher and Lecturer in the Language Development Group}

Archer also looks at some of the complexities arising from applied disciplines. She has just completed a research project $(2005,2006)$ looking at multimodality in the discipline of engineering.

Archer shows how engineering is closely allied to scientific discourse because as an academic discipline it is founded upon and validated by the academic discourse of science, and to a large extent, it has remained isolated from the pragmatics of engineering as a professional practice and from the social context of engineering (Johnston et al 1996, Goldman 1991, Bugliarello 1991, Beder 1999). Engineering is often seen merely as the application of science with all the principles of scientific practice assumed to cover those of engineering as well. The discourse of engineering thus coheres with Western Anglophone academic scientific discourse. Both function on a framework of binaries, privileging one subsystem of binaries: logic over emotion, academic ‘truth’ over personal experience, 
linearity over circularity, certainty over uncertainty and formality over informality (Lillis 2001: 81).

However, although the discourse of engineering science is still the dominant one in the engineering curriculum, there are some current shifts in the discipline of engineering and an acknowledgement of the limitations of a reliance solely on science to define engineering activity. Social needs and pressures shape engineering as much as engineering and technology shape the nature of society. So, the discipline of engineering is not constituted by a single discourse with impermeable boundaries. There are a number of discourses that define the nature and practice of engineering that exist in some tension with each other. These include management, economics, sociology, politics, and development.

Perhaps what is specific to engineering discourse as distinct from scientific discourse is a particular way of arguing, which takes the form of systematically evaluating phenomena against certain specified criteria in order to make enlightened decisions on the most appropriate fit for a particular purpose. This way of arguing is linked to the activity of design which is central to engineering practice. The design process begins with a selection of the problem to be addressed. The next step is to define the characteristics of an acceptable solution according to stated criteria. It is then necessary to generate alternative approaches to solving the problem, to review the alternatives against the specification, to decide on a preferred solution, and to document and communicate that solution (Johnston, Lee, McGregor 1996). Because engineering is based on problem-solving from first principles, and hypotheses are based in the physical world, it can be described as "design under constraint” (Wulf 2004: 313).

The following is an example of first year students' attempts to judge phenomena against stated criteria.

The sustainable development would include the new water supply system that can supply the whole village with clean and fresh water, the construction of the widely used roads to enhance on the transport infrastructure and the installation of 
electricity that is strong, clean and safe and can withstand weather conditions. All of this should be done at a relatively low price and the development must be environmentally friendly and must not expose the residents to health risks. (Introduction on a student poster, students' own emphasis)

Here the following criteria are specified: cost effective, environmentally friendly and risk free. However, this way of arguing or organizing knowledge is not yet fully internalized and inhabited by the student, and occasionally, it becomes part of the form rather than the substance. For example, in statements such as the following:

The criteria for development were developed so that the development should be done along those lines of development and any option that does not satisfy the criteria would not be considered (Introduction).

The selection of the suitable source was done considering the criteria for development that was made to ensure that the development is done along those lines of development and whichever source or option that do not comply with the criteria will not be considered. These criteria enabled the group to come up with the possible solutions that might help to sustain the village (Conclusion).

Here the emphasis on criteria as constraints fulfils the organizational function of the text rather than the meaning function. In this way, it functions as a kind of metalanguage, reflecting on the scientific organization of the text.

In engineering discourse, the criteria are the underlying belief system or ideology constructed in the text. Archer points out that it is important to highlight to students that couching argument in depersonalised academic discourse does not necessarily reduce the strength of the writer's conviction and it is possible to insert one's own identity in textual representations. It is also important to realize that the texts one encounters are not neutral, but are ideologically laden from particular perspectives. This awareness is part of becoming a critical producer and interpreter of texts. 
As Archer indicates, argument in the engineering discipline links the abstract to the context-specific by weighing up phenomena against certain set criteria. In organizing knowledge in this way, the processes of classifying occur at a high level, with classifications weighed against each other in complex, multi-faceted judgments. This way of arguing links the abstract to the particular, the general to the context-specific, innovation to pragmatism - all of which are crucial conceptual resources for students of engineering.

\section{Conclusion}

The deeper we delved into these disciplinary discourses, the more nuanced the picture of them has become. While Chihota showed the complex 'game' through which a writer of literary theory uses the conventions of his discipline to deploy his stance, Arend dealt with more explicit personal positionings by authors in a sub-discipline of linguistics. In economics, Paxton found that tutors were quite fixed and narrow in the instructions they gave students while lecturers indicated more of a nuanced picture, particularly in terms of what they expected from students. She explained these differences by noting that the discourse of economics itself is shifting and changing; it is a social science but moving strongly towards becoming a pure science in order to gain greater credibility. In the multidisciplinary context of the new curriculum in health sciences, Van Pletzen considered the shifts and changes that are likely to occur between the disciplinary discourses, while Archer discussed engineering, an applied science that draws on a variety of different discourses to define itself.

This has led the authors to question how best we should use an analysis like Hyland's in a developmental context. Hyland's corpus analysis presents quite a clearly defined sense of how disciplines work (or should work) which might provide useful background reading for writing consultants as they prepare to assist students with their writing. However, through our research and through our teaching, we have found that the picture of writer's stance in disciplinary discourses is much more complex than is revealed by means of a corpus analysis. Each writing task is unique and situated within a particular social context and each 
individual writer has to find a route through a particular disciplinary discourse that suits his/her style and fits that context. If conventions are set out as clear, simple rules, students might find themselves very constrained as they try to establish their own voices in their writing. They may find that writing in the new discourse and trying to observe these conventions robs them of their own voices. Hyland's corpus analysis raises one's awareness of the existence of these conventions, but it does not indicate the process of finding one's authorial role within these different genres. There is always a risk that teachers and consultants who use corpus analysis to guide their teaching may convey the idea that there is a particular fixed set of rules to be followed within each disciplinary discourse. As our own research into particular disciplines indicates, discourses are not stable or monolithic but varied, changing, contradictory and hybrid. This is perhaps particularly true in a country like South Africa, which is itself in the process of change and where we, as teachers, have to respond regularly to changing structures and changing discourses.

We have also gained insights into the ways in which we mediate students' acquisition of these discourses. It seems important that what needs to be made explicit is not so much the particular conventions as much as that conventions exist, are challenged by particular social environments and can change. Therefore our role should be to encourage students to enter into conversations with lecturers in order to tease out some of the complexities of the discourse. In the same way lecturers should be persuaded to articulate the conventions and requirements of their discipline and to show why and how particular conventions have arisen. Perhaps our particular role as writing consultants or language development practitioners is to point out that while undergraduate students are in a position of apprenticeship within the discipline, there may yet be opportunities where students can bring a particular knowledge of social practices that could contribute to the formulation of new discourses. 


\section{References}

Archer, A. 2007. Opening up spaces through Symbolic Objects: Drawing on students' resources in developing academic literacy practices in Engineering. English Studies in Africa. 49 (1)

Archer, A. 2006. A multimodal approach to academic 'literacies': problematizing the visual/verbal divide. Language and Education. 20 (6): 449 - 462.

Bakhtin, M.M. (Holquist, M. ed. and transl.) 1981. The Dialogic Imagination. Austin, Texas: University of Texas Press.

Bartholomae, D. 1985. Inventing the university. In M. Rose (ed.) When a Writer Can't Write. New York: Guildford Press: 34-165.

Baynham, M. 1995. Literacy Practices. Investigating Literacy in Social Contexts. London and New York: Longman.

Becher, T. and Trowler, P. 2001. Academic Tribes and Territories. Second Edition. Buckingham: Society for Research into Higher Education and Open University Press.

Beder, S. 1999. Beyond Technicalities: Expanding Engineering Thinking. In Journal of Professional Issues in Engineering. 125 (1): 12-18.

Bennet, T. 1990. Outside Literature. London and New York: Routledge. 106.

Bugliarello, G. 1991. The Social Function of Engineering: A Current Assessment. In Sladovich, Hedy (ed.) Engineering as a Social Enterprise. National Academy Press: Washington D.C.

Cliff, A. and Yeld, N. 2006. Section 3, Domain 1: Academic Literacy. In H. Griesel (ed.) Access and entry level benchmarks: the national benchmark tests project. Higher Education South Africa-HESA.

Foucault, M. 1970. The Order of Discourse. In R. Young. (ed.) 1981. Untying the Text. A post-structuralist reader. Boston/London/Henly: Routledge and Kegan Paul.

Granville, S. and Dison, L. 2005. Thinking about thinking: Integrating self-reflection into an academic literacy course Journal of English for Academic Purposes. 4, 2. 99-118.

Goldman, S. 1991. The Social Captivity of Engineering. In P. Durbin (ed.) Critical Perspectives on Nonacademic Science and Engineering. Bethlehem: Lehigh University press. 121-45.

Hasan, R. 2003. Globalization, literacy and ideology. In: World Englishes. 22, 4. 2003. London: Blackwell. 233-448. 
Hyland, K. 1999. Disciplinary discourses: writer stance in research articles. In C. Candlin and K. Hyland (eds.) Writing: Texts, Processes and Practices. London and New York: Longman. 99-121.

Hyland, K. 2000. Disciplinary Discourses. Harlow: Pearson Education Limited and Longman.

Ivanic, R. 1997. Writing and Identity: The discoursal construction of identity in academic writing. Amsterdam: John Benjamin.

Johnston, S., Lee, A., McGregor, H. 1996. Engineering as Captive Discourse. In Philosophy and Technology.1: $3-4$.

Klamer, A. 1990. The textbook presentation of economics discourse. In W. J. Samuels (ed.) Economics as Discourse: an analysis of the language of economists. Boston: Kluwer Academic: 129-154.

Leibowitz, B. and Mahomed, Y. 2000. Routes to Writing in Southern Africa. Cape Town: Silk Road Publishers.

Leibowitz, B. 2000. The importance of writing and teaching writing in the academy. In B. Leibowitz and Y. Mahomed (eds.) Routes to Writing in Southern Africa. Cape Town: Silk Road Publishers: 15-41.

Lillis, T. 1997. 'New voices in academia: the regulative nature of academic writing conventions’. In Language and Education. 11, 3.182-199.

Paxton, M. 2003. Ways in which Students Gain Access to University Discourses: the Intersection of the academic Curriculum with Student voices. In C. Prichard and P. Trowler (eds.) Realizing Qualitative Research into Higher Education. Aldershot. Ashgate Publishers. 21-39.

Paxton, M. 2004. Intertextuality in student writing: the intersection of the academic curriculum and student voices in first year economics assignments. Unpublished Doctoral Dissertation. University of Cape Town.

Paxton, M. 2006. Intertextual analysis: a research tool for uncovering the writer's emerging meaning. In L. Thesen and E. van Pletzen (eds.) Academic Literacies and the Languages of Change. London: Continuum.

Prinsloo, M . and Breier, M. 1996. The Social Uses of Literacy. Cape Town: SACHED Books and Amsterdam and Philadelphia: Benjamin Publishers. 
Rios, G. 2005. Contrasting Urban Literacies in Two Socio-economically Differentiated Neighbourhoods in Brazil. In A. Rogers (ed.) Urban Literacy: Communication, Identity and Learning in Development Contexts. Hamburg: Alsterdruck GmbH.

Street, B. V. 1996. Preface to The Social Uses of Literacy. Cape Town: SACHED Books and Amsterdam and Philadelphia: Benjamin Publishers.

Street, B. V. 1999. Meanings of Culture in Development: a case study from literacy. In A. Little and F. Leach (eds.) Schools and Economics in the developing World: Tensions and Conflicts. New York: Garland Press

Swales, J. 1993. The Paradox of Value: Six Treatments in Search of the Reader. In T. Dudley-Evans, W. Henderson and R. Backhouse (eds.) Economics and Language. London and New York: Routledge.

Van Pletzen, E. 2006. A body of reading: making 'visible' the reading experiences of first-year medical students. In L. Thesen and E. van Pletzen (eds.) Academic Literacies and the Languages of Change. London: Continuum.

Wulf, W.A. 2004. Some thoughts on Engineering as a Humanistic Discipline. In International Journal of Engineering Education. 20, 3. 313 - 314. 